\title{
Enteroaggregative Escherichia coli: A Pathogen Bridging the North and South
}

\author{
Teresa Estrada-Garcia • Iza Perez-Martinez • \\ Rodolfo Bernal-Reynaga $\cdot$ Mussaret B. Zaidi
}

Published online: 25 March 2014

(C) Springer International Publishing AG 2014

\begin{abstract}
Enteroaggregative Escherichia coli (EAEC) is a heterogeneous emerging enteric pathogen identified during the 1980s when EAEC strains were isolated from cases of acute and persistent diarrhea among infants in developing countries as well as traveler's diarrhea. Subsequently, EAEC strains were linked with foodborne outbreaks and diarrhea illness in adults and children from industrialized countries and HIV-infected subjects, and with the stunting of malnourished children living in impoverished countries. Today, EAEC is increasingly recognized as a major cause of acute diarrhea requiring hospitalization in children and of traveler's diarrhea worldwide. The defining phenotype of EAEC strains is the aggregative adherence (AA) pattern on epithelial cells. The role of AggR, a transcriptional regulator of several EAEC virulence genes, is a key factor in both understanding EAEC pathogenesis and defining typical EAEC (tEAEC) strains. The distribution of EAEC virulence genes among these strains is highly variable, and the identification of key virulence genes and their function in the setting of enteric disease presents ongoing challenges.
\end{abstract}

Keywords Enteroaggregative Escherichia coli (EAEC) ·

Escherichia coli $\cdot$ Epidemiology $\cdot$ Identification · Tropical medicine - GI infection - Aggregative adherence (AA) . Pathogen

T. Estrada-Garcia $(\bowtie) \cdot$ I. Perez-Martinez $\cdot$ R. Bernal-Reynaga Department of Molecular Biomedicine, CINVESTAV-IPN, Av IPN \#2508, Zacatenco, México, DF CP 07360, México e-mail: testrada@cinvestav.mx

\section{B. Zaidi}

Microbiology Research Laboratory and Pediatric Emergency Department, Hospital General O’Horán, Mérida, Yucatán, México

M. B. Zaidi

Infectious Diseases Research Unit, Hospital Regional de Alta Especialidad de La Península de Yucatán, Mérida, Yucatán, México

\section{Introduction}

Diarrheagenic Escherichia coli (DEC) groups are perhaps one of the most interesting new enteric pathogens described in the last 40 years. In contrast to other enteric pathogens identified during this period, such as Campylobacter jejuni and norovirus, the role of DEC strains in disease has been difficult to prove $[1,2]$, largely because most strains are biochemically indistinguishable from commensal E. coli strains isolated from the intestinal tract. Therefore, it became necessary to determine their pathogenic capability in volunteer studies $[3,4]$. DEC are classified within six groups based on clinical associations, phenotypic assays, and virulence factors: enterotoxigenic E. coli (ETEC); typical and atypical enteropathogenic E. coli (tEPEC, aEPEC); enteroinvasive E. coli (EIEC); enteroaggregative $E$. coli (EAEC); diffusely adherent $E$. coli (DAEC); and Shiga-toxin-producing E. coli (STEC) [5]. Each DEC pathotype is clinically, epidemiologically, and pathogenically distinct. In this review we will summarize EAEC history, epidemiology, pathogenesis, host susceptibility, and clinical manifestations, as well as current limitations to routine identification in the clinical lab setting.

\section{EAEC History and Epidemiology}

The distinctive characteristic of EAEC strains is their ability to produce a "stacked-brick" adherence pattern on HEp-2 epithelial cells, as described in a protocol developed by Cravioto et al. in 1979 [6] (Fig. 1). During the 1980s, using Cravioto's protocol, two independent groups reported that $E$. coli strains isolated from adult travelers to Mexico [7] and Peruvian infants [8] with diarrheal illness adhered in a stacked-brick fashion. The authors of the latter study used the term "aggregative adherence" (AA) to describe the E. coli strains, which were later named "enteroadherent-enteroaggregative," and 


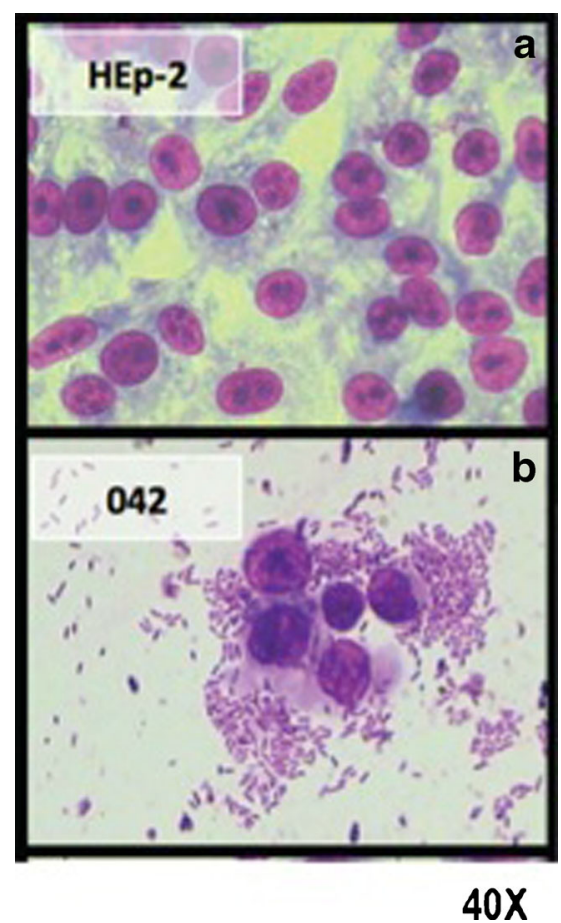

Fig. 1 Panel A, HEp-2 cells cultured in DMEM/tryptone; and Panel B, HEp-2 infected with EAEC 042 strain showing the characteristic aggregative adherence pattern ("stacked brick" adherence) [10••]

eventually shortened to "enteroaggregative" [8]. From these studies, the EAEC reference strains JM221 [7] and 042 [8] were identified. These EAEC isolates and others were tested in an adult volunteer study [4] in which it was observed that the 042 strain elicited diarrhea in the majority of challenged subjects, whereas the other EAEC strains did not. These early studies provided evidence of the strong heterogeneity of the EAEC strains as well as the host responses. The 042 isolate (serotype O44:H18) became the prototypic EAEC strain for the study of virulence factors, pathogenicity $[9 \bullet, 10 \bullet]$, genetic studies [10••], and animal models [11]. The EAEC 042 genome, which was characterized in 2010, comprises a circular chromosome of 5,241,977 bp and one plasmid of $113,346 \mathrm{bp}$, known as the "aggregative adherence plasmid" (pAA) [12]. The other EAEC reference strain used in animal models is JM221, which has been particularly useful in understanding the EAEC immune response in malnourished mice [13].

Shortly after EAEC strains were first described, Bhan et al. $[14,15]$ reported an association between EAEC strains and persistent diarrhea in Indian children. In 1991, Knutton et al. [16] found that E. coli strains isolated from children admitted with diarrheal symptoms at a London hospital adhered in a stacked-brick fashion. A landmark study in 1992 by Lima et al. [17] reported that EAEC persistent diarrhea was linked to growth shortfalls, decreased intellectual development, and death in impoverished Brazilian children. Follow-up studies of these children [18] revealed that not only children with
EAEC persistent diarrhea, but also those with EAEC infection, had increased levels of fecal lactoferrin, IL-8, and IL-1 $\beta$. In the same year, EAEC was linked to diarrhea in children with perinatal HIV infection in Zaire [19]. Likewise, EAEC was associated with diarrheal illness in an adult HIV patient in the U.S. [20] and among HIV-infected adults in Africa [21].

The identification of the AggR transcription activator encoded by the $\operatorname{agg} R$ gene on the pAA plasmid was a major step toward understanding EAEC pathogenesis $[9 \cdot, 22,23]$. The important role of AggR, a major EAEC transcriptional regulator of several plasmid- and chromosomal-borne EAEC virulence genes, led Nataro in 2005 to propose that 1) the presence of the AggR regulon may identify pathogenic EAEC strains (known as typical EAEC), and 2) epidemiologic and clinical investigations of diarrheal disease should include detection of typical EAEC. A hybrid E. coli strain (serotype O104:H4) was recently associated with a major foodborne outbreak in Europe [24, 25]. The strain was unique insofar as it carried several virulence genes characteristic of EAEC (including $\operatorname{aggR}$ ), as well as STEC and extraintestinal E. coli (ExPEC). During the spring of 2011, this strain sickened more than 4,300 previously healthy individuals, mainly adults, from 16 countries. More than 900 patients developed hemolytic uremic syndrome (HUS), and over 50 people died [25].

Studies of diarrheal illness worldwide have demonstrated that EAEC epidemiology is very different from that described for tEPEC and ETEC. For instance, during the last 30 years, tEPEC has been almost exclusively isolated in children, mainly under the age of 1 year, from less developed regions of the world [26-28]. ETEC is considered the major pathogen associated with weanling diarrhea among children in the developing world [28]. In contrast, almost from the time that they were first described EAEC strains have been associated with diarrheal illness in previously healthy children and adults from industrialized countries without history of international traveling, as well as in children from the developing world [10••, $16,29-32]$.

After the 2011 outbreak of the hybrid EAEC-STECEXPEC O104:H4 strain, an increased number of epidemiological studies sought both EAEC and EAEC hybrid strains in patients with diarrhea, particularly in children from less developed regions of the world [33-36]. The distribution of EAEC infection and illness affecting different populations worldwide is shown in Table 1 [10••, 37-39].

Diarrheal illness remains among the leading causes of morbidity among children less than 5 years of age worldwide, as well as a major cause of death among children younger than 2 years from Sub-Saharan Africa, South Asia, and Latin America [40]. EAEC is currently recognized as a major bacterial agent of acute diarrhea illness. Several studies conducted in children from Latin America, Asia, Africa, and former Eastern European countries have identified EAEC more frequently than any other bacterial pathogen [10••, 33-38]. 
Table 1 EAEC distribution and clinical presentation by geographic region

\begin{tabular}{|c|c|c|c|}
\hline Affected population & Clinical presentation & Less developed regions & Industrialized regions \\
\hline Infants and children $<5$ years & Acute diarrhea & $\begin{array}{l}\text { Latin America, South and Southeast Asia, Africa, } \\
\text { Eastern Europe }\end{array}$ & Europe, U.S. \\
\hline Children $<5$ years & Persistent diarrhea & India, Brazil, Mexico, Ghana & UK, Germany, U.S. \\
\hline $\begin{array}{l}\text { HIV-infected patients (adults and } \\
\text { children) }\end{array}$ & Acute and persistent diarrhea & $\begin{array}{l}\text { Senegal, Central African Republic, Zambia, Peru, } \\
\text { Uganda, Zaire, Brazil, South Africa }\end{array}$ & U.S. \\
\hline Adults & Acute diarrhea $^{*}$ & India, Nigeria, Ghana & U.S., UK \\
\hline Children and adults & Traveler's diarrhea & & Canada, U.S., Europe \\
\hline Older children ( $>5$ years) and adults & $\begin{array}{l}\text { Acute infections and foodborne } \\
\text { outbreaks }\end{array}$ & & U.S., Europe, Japan \\
\hline Malnourished children & Persistent diarrhea & Brazil, Ghana & \\
\hline
\end{tabular}

* Distinct from traveler's diarrhea

Studies conducted in the U.S., Europe, and Israel have also associated EAEC with diarrheal illness in young children [as revised by $10 \bullet \bullet, 38]$. In the U.S., EAEC strains are the most common bacterial cause of diarrheal illness in young children, surpassing Campylobacter and Salmonella [31, 41]. Importantly, several of these studies have shown that EAEC was the leading bacterial pathogen in children hospitalized for acute diarrhea in both less developed and industrialized regions [as revised by $10 \bullet \bullet, 41-43]$.

Conversely, EAEC is much more prevalent among adults with diarrhea in industrialized countries [31, 32, 44, 45] than those from developing regions. In a recent retrospective study of UK children and adults that included over 2,000 stool specimens, EAEC was identified in approximately $5 \%$ of subjects [32]. Likewise, EAEC was the most common bacterium identified in studies of diarrhea etiology conducted in emergency departments and outpatient clinics among adults with diarrhea from the U.S., [31, 44]. In addition, several EAEC foodborne outbreaks in Japan have involved older children ( $>5$ ) and adults [30]. A massive outbreak that occurred in Japan was linked with EAEC that was significantly associated with the consumption of school lunches [30]. Of the 6,636 children and adolescents who ate the school lunch, 2,697 developed gastroenteritis, with an attack rate of approximately $41 \%$ and an incubation period of 40-50 hours. Reports on diarrheal disease in older children and adult residents from developing countries are scarce [46]. In 1997, Pai et al. reported an EAEC outbreak in India affecting all age groups, with an overall attack rate of $15 \%$ [47]. EAEC has also been linked to adult diarrheal episodes in Nigeria [48] and Ghana [49]. The lower prevalence of EAEC in adult diarrheal disease in developing and less developed countries may be due to protective immunity, although it is also possible that it is due to the paucity of studies on adult diarrhea in these regions.

Large epidemiological studies worldwide have indicated a rate of approximately 3.2 episodes of diarrhea per child, and it has been estimated that between $3 \%$ and $20 \%$ of these episodes correspond to persistent diarrhea ( $>14$ days) [50].
Since the first association of EAEC with persistent diarrhea in Indian children, this bacterium has been identified as a cause of chronic diarrhea in children from less developed countries as well as from Europe and the U.S. [as revised by $10 \bullet \bullet$ ]. Whether EAEC is the major bacterial agent causing persistent diarrhea in these regions remains to be determined. From a public health standpoint, as mentioned previously, the most significant impact of EAEC persistent diarrhea and EAEC infection is on malnourished children living in impoverished regions and its association with stunting [17, 18, 51]. Stunting (length for age Z-score $<-2$ ) is associated with increased severity and duration of infectious disease episodes. The World Health Organization has estimated that $32 \%$ of children younger than 5 years living in impoverished areas are stunted $[52,53 \bullet \cdot$. Unfortunately, linear growth deficits that occur in early life are not fully reversible, and these permanent deficits are a marker of an enduring loss of human potential. Stunting not only occurs in children from poorer developing countries, but also in those living in impoverished slums from middleincome countries [17].

Over the years, studies have linked diarrheal illness with EAEC infection in both HIV-infected adults and children in Africa and South America [10••, 39] and in adults in the U.S. [54]. It remains to be determined whether EAEC is also associated with diarrhea illness in HIV patients from other developing and industrialized countries.

Traveler's diarrhea (TD) is the most common illness affecting individuals traveling from industrialized countries to less developed areas of the world. EAEC strains have been implicated as second only to ETEC as the most frequently isolated pathogen from traveler's diarrhea patients returning from Latin America and Southeast Asia [55, 56]. TD occurs in 15$50 \%$ of visitors from industrialized countries to low- and middle-income regions, and up to 40 million cases of TD are reported each year [57••, 58]. Depending upon length of stay, TD may affect up to $80 \%$ of travelers to high-risk destinations (WHO). In addition, it has been reported that a portion of patients with TD developed irritable bowel 
syndrome (IBS) and chronic gastrointestinal symptoms [57••, $59,60]$. The precise role of EAEC infection in IBS and chronic gastrointestinal symptoms has yet to be elucidated.

\section{Pathogenesis}

Data accumulated from several studies have suggested three major features of EAEC pathogenesis: 1) abundant adherence to the intestinal mucosa and biofilm formation over enterocyte surface, 2) production of enterotoxins and cytotoxins, and 3) induction of mucosal inflammation, intestinal secretion, and damage $[10 \bullet \bullet, 61 \bullet \cdot$, (Fig. 2).

As previously mentioned, most of our knowledge of EAEC pathogenesis has come from the characterization of virulence factors present in the prototype 042 EAEC strain that causes diarrhea in healthy volunteers. EAEC pathogenomic studies have focused on the transcriptional regulator AggR, a member of the AraC/XylS family of bacterial transcriptional activators. It has been shown that AggR activates the expression of at least 44 chromosomal- and plasmid-borne genes, including multiple EAEC virulence factors [9॰]. As discussed previously, AggR has been proposed as the defining factor for typical
EAEC strains [22]. However, the genes encoding for numerous adhesins, toxins, and proteins associated with virulence are highly variable among strains $[10 \bullet \cdot, 36]$, and this heterogeneity precludes a clear definition of EAEC virulence genes associated with illness and intestinal inflammation.

\section{Adherence and Biofilm Formation}

As is the case for most pathogenic enteric bacteria, attachment to the intestinal mucosa is an essential step in colonization and production of disease by EAEC. Since the defining feature of EAEC strains is their ability to produce the stacked-brick pattern, this results in an abundant adherence of these bacteria to the intestinal mucosa. EAEC adherence has been characterized as a biofilm composed of aggregates of bacteria in association with a thick mucus layer [62]. The AA pattern is associated with both fimbrial and afimbrial adhesins. The first fimbrial structures described in EAEC were the aggregative adhesion fimbria (AAF), of which at least four variants have been identified. All AAF are encoded in large pAA plasmids. AAF II has been shown to bind extracellular matrix cell components of the intestinal mucosa, and it appears to confer autoaggregation and biofilm formation as well. In EAEC

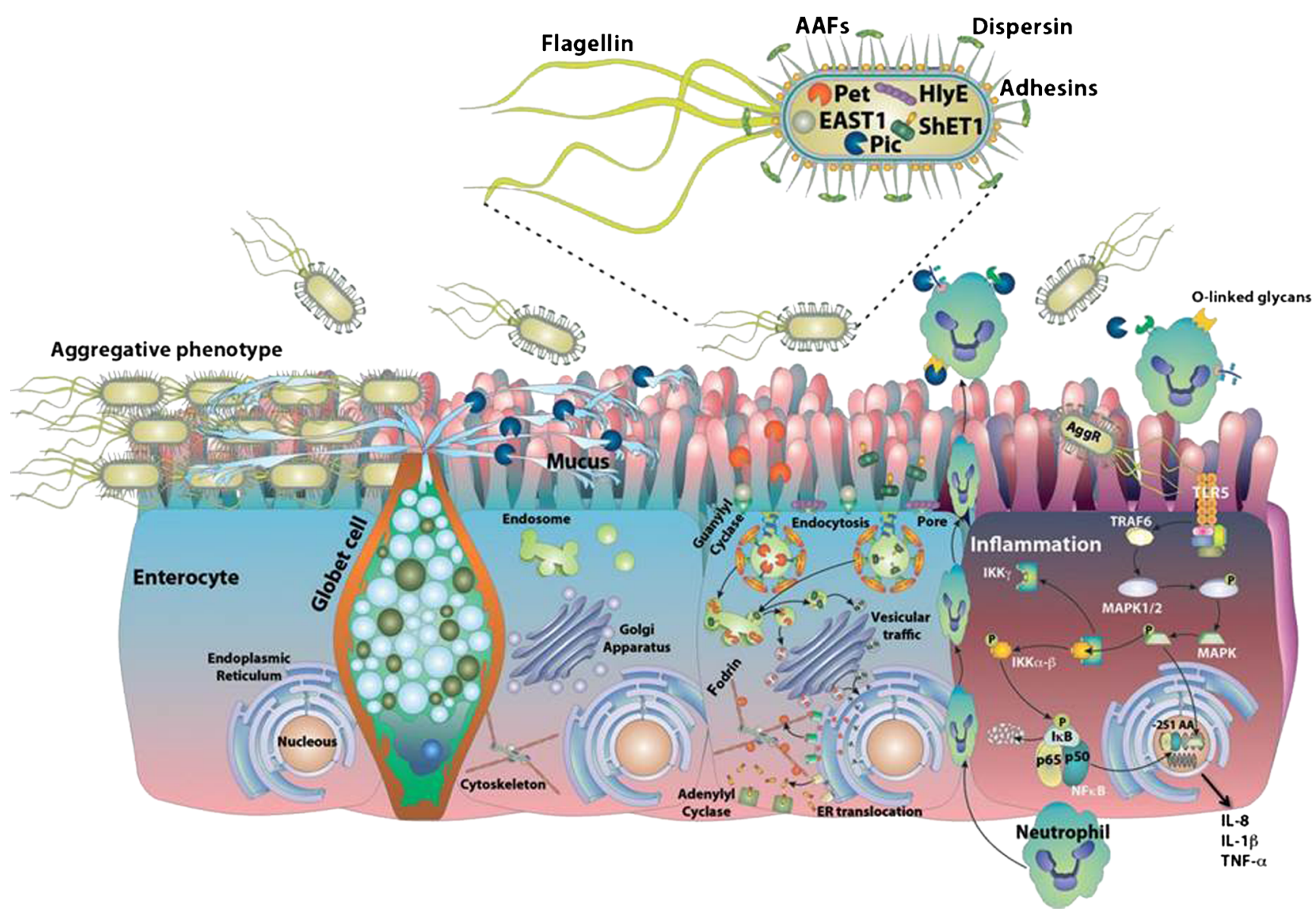

Fig. 2 Schematic representation of EAEC virulence factors and their targets on mucosal epithelium cells. Taken from Estrada-Garcia T and NavarroGarcia F, FEMS Immunology and Medical Microbiology $201266: 281-298$ 
strains lacking AAF II, the heat-resistant agglutinin (hra1) that is chromosomally encoded plays a role similar to AAF II in autoaggregation and biofilm formation. It has been shown that shF genes of Shigella flexneri and Staphylococcus epidermidis homologs are also required for biofilm formation $[63,64]$. It has also been shown that the biofilm formation is a common phenomenon among EAEC isolates and that multiple genes associated with biofilm formation are regulated by $\operatorname{agg} R$ [65]. Another molecule involved in EAEC pathogenesis is dispersin, an antiaggregative secreted protein encoded by the aap gene [66]. Dispersin is translocated by the antiaggregative transporter (AaT) system, which acts by decreasing bacterial autoaggregation and allowing EAEC dispersion along the intestinal mucosa. Various studies have shown that EAEC isolates from patients may preferentially adhere to the jejunal, ileal, or colonic mucosae, another example of EAEC heterogeneity.

\section{Production of Enterotoxins and Cytotoxins}

After adherence, EAEC is capable of producing several toxins and cytotoxins that may cause microvillus vesiculation, enlarged crypt openings, and increased epithelial extrusion. Among these toxins are the E. coli heat-stable enterotoxin 1 (EAST1) that activates chloride channels; plasmid-encoded toxin (pet), a cytoskeleton-altering protein; Shigella enterotoxin 1 (SHET1) that also induces intestinal secretion; and the protein involved in intestinal colonization (pic) that has a mucinase activity and is involved in serum resistance. An uncharacterized toxin identified in genome sequencing and metabolic profiling screens includes a potential hemolysin encoded by the $h l y E$ gene that has pore-forming hemolytic activity and cytolytic effects [67]. Additionally, the gene encoding for the Shigella extracellular protease (sepA), with IgA endopeptidase activity, which was originally described in S. flexneri [68] was recently identified among EAEC strains and was strongly associated with diarrhea [36]. Several other putative virulence factors will surely be characterized in the coming years, as our knowledge of this pathogen is increasingly very rapidly.

Almost simultaneous with adherence, EAEC induces a host inflammatory response. The initial inflammatory response to EAEC infection is dependent upon the host innate immune system and type of EAEC strain causing the infection. The role of putative virulence genes and clinical outcomes is not well understood. However, the presence of several EAEC virulence factors (such as flagellin, AggR, AAF fimbria, and dispersin) correlate with elevated levels of fecal cytokines such as interleukin (IL)-1ra, IL-1 $\beta$, IL-8, interferon- $\gamma$, and inflammatory markers that include lactoferrin, fecal leukocytes, and occult blood [69-71]. We have also shown that when 042 strains are cultured with colonic epithelial Caco-2 cells, they can induce the production and early release not only of IL-8, a principal chemoattractant for polymorphonuclear (PMN) leukocytes, but also of several other proinflammatory cytokines (IL-1 $\beta$, IL-6, IL-12, and TNF), as well as IL-10, a regulatory cytokine (BernalReynaga paper in preparation). In addition, in vitro studies have shown that EAEC induces the activation of mitogenactivated protein kinases (MAPK) on intestinal cells, which in turn activates the transcriptional factor NF- $\mathrm{kB}$, leading to the secretion of IL-8 and potentially other cytokines [72, 73]. EAEC also activates the production of eicosanoid-based PMN (including neutrophils) chemoattractant, which leads to the recruitment and transmigration of neutrophils to the gut mucosa, causing intestinal damage that may promote EAEC colonization [74]. Both cytokine production and PMN transmigration contribute to EAEC pathogenesis and are a hallmark of inflammatory infectious diarrhea.

\section{Host Susceptibility}

There is increasing evidence that EAEC strains are very diverse, and consequently, the host response is also very heterogeneous $[10 \bullet \bullet]$. A study conducted on the natural history of EAEC and ETEC diarrhea among U.S. adult travelers during a four-week period after arrival to Mexico revealed that 1) in contrast to ETEC infection, to which adult travelers are most susceptible during the first weeks of exposure, travelers remain susceptible to EAEC infection throughout their stay; 2) the number of subjects with EAEC colonization increased over time, whereas the number of cases of EAEC diarrhea decreased with the length of stay; and 3) none of the 16 patients that developed EAEC-diarrhea had a repeat episode due to this bacteria. These observations suggest that immunity to symptomatic EAEC diarrhea may have been acquired early during travel, but that resistance to asymptomatic enteric infection did not occur in this adult population. Genetic susceptibility to EAEC infection has been observed in adult subjects who develop TD, suggesting that a singlenucleotide polymorphism in the IL-8 gene promoter region is strongly associated with both EAEC diarrheal illness and greater levels of fecal IL-8 [70]. Additionally, polymorphisms in lactoferrin, osteoprotegerin, and CD14 promoter genes have been associated with increased susceptibility to TD caused by both ETEC and EAEC [75]. In order to further enhance our understanding of EAEC infection and illness, it is necessary to conduct studies of natural EAEC infection, host genetic susceptibility, and immunity in endemic populations.

\section{Clinical Manifestations and Treatment}

The clinical features of EAEC illness have been described in volunteer studies, outbreaks, and sporadic cases. The 
characteristic clinical picture includes watery secretory diarrhea (often with mucus, with or without blood), low-grade fever, abdominal pain, nausea, and vomiting $[4,15,38,76$, 77]. While bloody diarrhea is not a distinctive feature of EAEC illness, Cravioto et al. (1991) [78] reported that onethird of affected infants under 2 years of age had grossly bloody stools. In a recent study that we conducted among children hospitalized for diarrhea, EAEC was identified in approximately $7 \%$. Of those 20 patients in whom EAEC was the only etiological agent identified, $55 \%$ had mucus in feces, $50 \%$ had more than six stool movements per day, and $10 \%$ had bloody stools (authors' unpublished data). Overall, EAEC diarrheal episodes have been frequently associated with the presence of mucus, PMNs, and lactoferrin in stools $[44,51,69,71,77]$.

In children, treatment of bacterial gastroenteritis, including EAEC, is primarily supportive and directed toward maintaining hydration and electrolyte balance. Antibiotic therapy is rarely indicated and should be deferred until culture results are available. Oral rehydration therapy (ORT) is the preferred treatment for fluid and electrolyte losses caused by diarrhea in children with mild-to-moderate dehydration. Intravenous hydration is often administered for severe dehydration or when vomiting prevents ORT $[79,80]$. EAEC antimicrobial therapy should be used in cases of severe diarrheal disease to reduce the duration of illness, particularly because of its association with persistent diarrhea in children. Because experts in travel medicine discourage the use of absorbable antimicrobial agents for TD prophylaxis, the poorly absorbed antibiotic rifaximin has been proposed for prevention of traveler's diarrhea $[57 \bullet \bullet]$.

The progressive increase in antibiotic resistance among EAEC strains in developing countries is cause for concern [42, 81, 82]. Several investigators have suggested that lactoferrin may protect infants from gastrointestinal infections, including EAEC, and may be an alternative treatment for antibiotic-resistant EAEC strains [83].

\section{Controversies in EAEC Identification}

For years, the gold standard for EAEC identification relied on the recognition of the characteristic AA (stacked-brick) pattern on human epithelial cells (HEp-2-adherent assay) [6]. Since E. coli is part of the human intestinal microbiota, laboratory identification of DEC includes the testing of at least five colonies in order to increase the probability of isolating a pathogenic strain. Unfortunately, there are several inherent limitations in the HEp-2-adherent assay with respect to surveillance systems and large epidemiological studies of patients or food. It is labor-intensive, expensive, requires welltrained personnel, and can only be performed in laboratories that culture cell lines. Furthermore, it cannot distinguish between pathogenic and non-pathogenic strains. The recognition of strains carrying the AggR regulon as typical EAEC (tEAEC) strains was undoubtedly a major step in EAEC identification [20]. The high prevalence of tEAEC strains among EAEC isolates previously identified by the HEp- 2 cell assay was illustrated when studies revealed that $100 \%$ of EAEC reference strains [84] and $80 \%$ of isolates from subjects with [85] and $70 \%$ from subjects without diarrhea [42] harbored the $\operatorname{agg} R$ gene. Furthermore, microarray DNA analyses of a set of EAEC strains confirmed that tEAEC isolates carrying $\operatorname{agg} R$ shared a package of common virulence genes comprising a large number of conserved plasmid and chromosomal loci [86]. It was also observed that the presence of gross mucus and fecal leukocytes in the stools of patients infected with EAEC were associated with strains carrying $\operatorname{agg} R$ in combination with other virulence genes [42, 44, 87, $88]$.

Although case-control studies have isolated tEAEC more frequently from ill subjects than healthy controls [87, 89], other studies have not observed significant differences between the two groups [43, 44]. Several studies have consistently shown that tEAEC isolates from subjects with diarrhea frequently carried additional virulence genes $[9 \bullet, 36,43,82$, 84, 90]. A current challenge, therefore, is to identify key virulence genes defining tEAEC strains associated with both illness and intestinal inflammation. Despite numerous tEAEC molecular genetics characterization studies, recognition of these key defining genes remains elusive $[10 \bullet \bullet, 36]$. In summary, the current evidence suggests that typical EAEC strains are widely distributed, that $\operatorname{aggR}$ is a good marker for their identification, that not all tEAEC strains are pathogenic, and that a set of currently undefined virulence genes, probably controlled by the AggR master regulon, are associated with pathogenic EAEC strains.

\section{Conclusions}

EAEC infections are a major cause of diarrhea in poor and middle-income populations in developing and industrialized countries alike. EAEC epidemiology is unique, as it differs from that of other DEC pathotypes (ETEC, tEPEC) and enteropathogens traditionally associated with poverty such

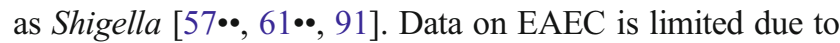
the constraints for routine identification in clinical laboratories. Although several studies have demonstrated that tEAEC strains are associated with unfavorable clinical outcomes, its true global public health implications have yet to be determined. Surveillance systems in developed countries should include tEAEC identification, particularly in light of the large EAEC foodborne outbreaks in Japan and Europe [25, 30]. The high prevalence of tEAEC in childhood diarrhea and the role of this bacterium in persistent diarrhea, intestinal 
inflammation, and stunting in children living in poor countries and in impoverished conditions in middle-income countries support the need for more extensive studies in developing countries as well $[17,51]$. One of the major challenges in the field today is in identifying a set of key virulence genes that can define those tEAEC strains associated with both illness and intestinal inflammation.

Acknowledgments This work was supported by CONACyT (Consejo Nacional de Ciencia y Tecnología) grant 128779 to T.E.G.; CONACyT scholarship for R.B.R. (219326), and by National Institute of Health grant (U01AI082110) to M.B.Z., I. P.M., and T.E.G.

\section{Compliance with Ethics Guidelines}

Conflict of Interest Teresa Estrada-Garcia, Iza Perez-Martinez, Rodolfo Bernal-Reynaga, and Mussaret B. Zaidi declare that they have no conflict of interest.

Human and Animal Rights and Informed Consent This article does not contain any studies with human or animal subjects performed by any of the authors.

\section{References}

Papers of particular interest, published recently, have been highlighted as:

- Of importance

-• Of major importance

1. Altekruse SF, Stern NJ, Fields PI, Swerdlow DL. Campylobacter jejuni-an emerging foodborne pathogen. Emerg Infect Dis. 1999;5: 28-35.

2. Widdowson MA, Sulka A, Bulens SN, et al. Norovirus and foodborne disease, United States, 1991-2000. Emerg Infect Dis. 2005;11:95-102.

3. DuPont HL, Formal SB, Hornick RB, et al. Pathogenesis of Escherichia coli diarrhea. N Engl J Med. 1971;285:1-9.

4. Nataro JP, Yikang D, Cookson S, et al. Heterogeneity of enteroaggregative $E$. coli virulence demonstrated in volunteers. $\mathrm{J}$ Infect Dis. 1995;171:465-8.

5. Nataro JP, Kaper JB. Diarrheagenic Escherichia coli. Clin Microbiol Rev. 1998;11:142-201.

6. Cravioto A, Gross RJ, Scotland SM, Rowe B. An adhesive factor found in strains of Escherichia coli belonging to the traditional infantile enteropathogenic serotypes. Curr Microbiol. 1979;3:95-9.

7. Mathewson JJ, Johnson PC, DuPont HL, et al. A newly recognized cause of travelers' diarrhea: enteroadherent Escherichia coli. J Infect Dis. 1985;151:471-5.

8. Nataro JP, Kaper JB, Robins Browne R, et al. Patterns of adherence of diarrheagenic Escherichia coli to HEp-2 cells. Pediatr Infect Dis J. 1987;6:829-31.

9. Morin N, Santiago AE, Ernst RK, et al. Characterization of the AggR regulon in enteroaggregative Escherichia coli. Infect Immun. 2013;81:122-32. This article describes the number of genes including several virulence genes under the control of the master AggR regulon.

10.• Estrada-Garcia T, Navarro-Garcia F. Enteroaggregative Escherichia coli pathotype: a genetically heterogeneous emerging foodborne enteropathogen. FEMS Immunol Med Microbiol. 2012;66:281-
98. This review described the current knowledge of EAEC pathogenesis and epidemiology.

11. Philipson CW, Bassaganya-Riera J, Hontecillas R. Animal models of enteroaggregative Escherichia coli infection. Gut Microbes. 2013;4:281-91.

12. Chaudhuri RR, Sebaihia M, Hobman JL, et al. Complete genome sequence and comparative metabolic profiling of the prototypical enteroaggregative Escherichia coli strain 042. PLoS One. 2010;5: e8801.

13. Philipson CW, Bassaganya-Riera J, Viladomiu M, et al. The role of peroxisome proliferator-activated receptor $\gamma$ in immune responses to enteroaggregative Escherichia coli infection. PLoS One. 2013;8: e57812.

14. Bhan MK, Khoshoo V, Sommerfelt H, et al. Enteroaggregative Escherichia coli and Salmonella associated with nondysenteric persistent diarrhea. Pediatr Infect Dis J. 1989;8:499-502.

15. Bhan MK, Raj P, Levine MM, et al. Enteroaggregative Escherichia coli associated with persistent diarrhea in a cohort of rural children in India. J Infect Dis. 1989;159:1061-4.

16. Knutton S, Phillips AD, Smith HR, et al. Screening for enteropathogenic Escherichia coli in infants with diarrhea by the fluorescentactin staining test. Infect Immun. 1991;59:365-71.

17. Lima AA, Fang G, Schorling JB, et al. Persistent diarrhea in northeast Brazil: etiologies and interactions with malnutrition. Acta Paediatr. 1992;381:39-44.

18. Steiner TS, Lima AA, Nataro JP, Guerrant RL. Enteroaggregative Escherichia coli produce intestinal inflammation and growth impairment and cause interleukin- 8 release from intestinal epithelial cells. J Infect Dis. 1998;177:88-96.

19. Pavia AT, Long EG, Ryder RW, et al. Diarrhea among African children born to human immunodeficiency virus 1-infected mothers: clinical, microbiologic and epidemiologic features. Pediatr Infect Dis J. 1992;11:996-1003.

20. Mayer HB, Wanke CA. Enteroaggregative Escherichia coli as a possible cause of diarrhea in an HIV-infected patient. N Engl J Med. 1995;332:273-4.

21. Mathewson JJ, Jiang ZD, Zumla A, et al. HEp-2 cell-adherent Escherichia coli in patients with human immunodeficiency virusassociated diarrhea. J Infect Dis. 1995;171:1636-9.

22. Nataro JP. Enteroaggregative Escherichia coli pathogenesis. Curr Opin Gastroenterol. 2005;21:4-8.

23. Dudley EG, Thomson NR, Parkhill J, et al. Proteomic and microarray characterization of the AggR regulon identifies a pheU pathogenicity island in enteroaggregative Escherichia coli. Mol Microbiol. 2006;61:1267-82.

24. Mariani-Kurkdjian P, Bingen E. Escherichia coli 0104:H4: a hybrid pathogen. Arch Pediatr. 2012;3:S97-100. French.

25. Grad YH, Lipsitch M, Feldgarden M, et al. Genomic epidemiology of the Escherichia coli O104:H4 outbreaks in Europe, 2011. Proc Natl Acad Sci U S A. 2012;109:3065-70.

26. Ochoa TJ, Contreras CA. Enteropathogenic Escherichia coli infection in children. Curr Opin Infect Dis. 2011;24:478-83.

27. Estrada-Garcia T, Lopez-Saucedo C, Thompson-Bonilla R, et al. Association of diarrheagenic Escherichia coli pathotypes with infection and diarrhea among Mexican children and association of atypical Enteropathogenic E. coli with acute diarrhea. J Clin Microbiol. 2009;47:93-8.

28. Kotloff KL, Nataro JP, Blackwelder WC, et al. Burden and aetiology of diarrhoeal disease in infants and young children in developing countries (the Global Enteric Multicenter Study, GEMS): a prospective, case-control study. Lancet. 2013;382:209-22.

29. Chan KN, Phillips AD, Knutton S, et al. Enteroaggregative Escherichia coli: another cause of acute and chronic diarrhoea in England? J Pediatr Gastroenterol Nutr. 1994;18:87-91.

30. Itoh Y, Nagano I, Kunishima M, Ezaki T. Laboratory investigation of enteroaggregative Escherichia coli $\mathrm{O}$ untypeable:H10 associated 
with a massive outbreak of gastrointestinal illness. J Clin Microbiol. 1997;35:2546-50.

31. Nataro JP, Mai V, Johnson J, et al. Diarrheagenic Escherichia coli infection in Baltimore, Maryland, and New Haven, Connecticut. Clin Infect Dis. 2006;43:402-7.

32. Chattaway MA, Harris R, Jenkins C, et al. Investigating the link between the presence of enteroaggregative Escherichia coli and infectious intestinal disease in the United Kingdom, 1993 to 1996 and 2008 to 2009. Euro Surveill 2013,18(37).

33. Pabalan N, Singian E, Jarjanazi H, Steiner TS. Enteroaggregative Escherichia coli and acute diarrhea in children: a meta-analysis of South Asian populations. Eur J Clin Microbiol Infect Dis. 2013;32: 597-607.

34. Dutta S, Guin S, Ghosh S, et al. Trends in the prevalence of diarrheagenic Escherichia coli among hospitalized diarrheal patients in Kolkata, India. PLoS One. 2013;8:e56068.

35. Lima IF, Boisen N, Quetz Jda S, et al. Prevalence of enteroaggregative Escherichia coli and its virulence-related genes in a case-control study among children from north-eastern Brazil. J Med Microbiol. 2013;62:683-93.

36. Boisen N, Scheutz F, Rasko DA, et al. Genomic characterization of enteroaggregative Escherichia coli from children in Mali. J Infect Dis. 2012;1:431-44.

37. Dow MA, Tóth I, Malik A, et al. Phenotypic and genetic characterization of enteropathogenic Escherichia coli (EPEC) and enteroaggregative E. coli (EAEC) from diarrhoeal and non-diarrhoeal children in Libya. Comp Immunol Microbiol Infect Dis. 2006;29:100-13.

38. Shazberg G, Wolk M, Schmidt H, et al. Enteroaggregative Escherichia coli Serotype O126:H27, Israel. Emerg Infect Dis. 2003;9:1170-3.

39. Garcia C, Chincha O, Leon M, Iglesias D, Barletta F, Mercado E, et al. High frequency of diarrheagenic Escherichia coli in human immunodeficiency virus (HIV) patients with and without diarrhea in Lima, Peru. Am J Trop Med Hyg. 2010;82:1118-20.

40. Parashar UD, Hummelman EG, Bresee JS, et al. Global illness and deaths caused by rotavirus disease in children. Emerg Infect Dis. 2003;9:565-72.

41. Cohen MB, Nataro JP, Bernstein DI, et al. Prevalence of diarrheagenic Escherichia coli in acute childhood enteritis: a prospective controlled study. J Pediatr. 2005;146:54-61.

42. Aslani MM, Alikhani MY, Zavari A, et al. Characterization of enteroaggregative Escherichia coli (EAEC) clinical isolates and their antibiotic resistance pattern. Int J Infect Dis. 2010;15:e136-9.

43. Regua-Mangia AH, Gomes TA, Vieira MA, et al. Frequency and characteristics of dirrheoeagenic Escherichia coli strains isolated from children with and without diarrhoea in Rio de Janeiro, Brazil. J Infect. 2004;48:161-7.

44. Cennimo DJ, Abbas A, Huang DB, Chiang T. The prevalence and virulence characteristics of enteroaggregative Escherichia coli at an urgent-care clinic in the USA: a case-control study. J Med Microbiol. 2009;58:403-7.

45. Wilson A, Evans J, Chart H, et al. Characterisation of strains of enteroaggregative Escherichia coli isolated during the infectious intestinal disease study in England. Eur J Epidemiol. 2001;17:1125-30.

46. Fischer Walker CL, Sack D, Black RE. Etiology of diarrhea in older children, adolescents and adults: a systematic review. PLoS Negl Trop Dis. 2010;4:e768.

47. Pai M, Kang G, Ramakrishna BS, et al. An epidemic of diarrhoea in south India caused by enteroaggregative Escherichia coli. Indian J Med Res. 1997;106:7-112.

48. Okeke IN, Ojo O, Lamikanra A, Kaper JB. Etiology of acute diarrhea in adults in southwestern Nigeria. J Clin Microbiol. 2003;41:4525-30.

49. Opintan JA, Bishar RA, Newman MJ, Okeke IN. Carriage of diarrhoeagenic Escherichia coli by older children and adults in Accra, Ghana. Trans R Soc Trop Med Hyg. 2010;104:504-6.
50. Zella GC, Israel EJ. Chronic diarrhea in children. Pediatr Rev. 2012;33:207-17.

51. Opintan JA, Newman MJ, Ayeh-Kumi PF, et al. Pediatric diarrhea in southern Ghana: etiology and association with intestinal inflammation and malnutrition. Am J Trop Med Hyg. 2010;83:936-43.

52. Kosek M, Haque R, Lima A, et al. Fecal markers of intestinal inflammation and permeability associated with the subsequent acquisition of linear growth deficits in infants. Am J Trop Med Hyg. 2013;88(2):390-6.

53.• Sarkar R, Sivarathinaswamy P, Thangaraj B, et al. Burden of childhood diseases and malnutrition in a semi-urban slum in southern India. BMC Public Health. 2013;13:87. This article describes the burden of several infectious diseases on malnourished children that lead to stunting.

54. Wanke CA, Mayer H, Weber R, et al. Enteroaggregative Escherichia coli as a potential cause of diarrheal disease in adults infected with human immunodeficiency virus. J Infect Dis. 1998; 178:185-90.

55. Paredes-Paredes M, Okhuysen PC, Flores J, et al. Seasonality of diarrheagenic Escherichia coli pathotypes in the US students acquiring diarrhea in Mexico. J Travel Med. 2011;18:121-5.

56. Ahn JY, Chung JW, Chang KJ, et al. Clinical characteristics and etiology of travelers' diarrhea among Korean travelers visiting South-East Asia. J Korean Med Sci. 2011;26:196-200.

$57 . \bullet$ de la Cabada Bauche J, DuPont H. New Developments in Traveler's Diarrhea. Gastroenterol Hepatol. 2011;7:88-95. This review described at that moment the current knowledge of traveler's diarrhea including epidemiology, prevention and treatment.

58. World Tourism Organization: Tourism highlights 2009 ed. United Nations World Tourism Organization, Geneva 2009.

59. Okhuysen PC, Jiang ZD, Carlin L, et al. Post-diarrhea chronic intestinal symptoms and irritable bowel syndrome in North American travelers to Mexico. Am J Gastroenterol. 2004;99:1774-8.

60. Sobieszczańska BM, Osek J, Waśko-Czopnik D, et al. Association of enteroaggregative Escherichia coli with irritable bowel syndrome. Clin Microbiol Infect. 2007;13:404-7.

61.• Croxen MA, Law RJ, Scholz R, et al. Recent advances in understanding enteric pathogenic Escherichia coli. Clin Microbiol Rev. 2013;26:822-80. This review on diarrheagenic E. coli pathotypes briefly describes their pathogenesis and epidemiology. In the EAEC section highlights the epidemiology of EAEC-STEC hybrid strains.

62. Nataro JP, Hicks S, Phillips AD, et al. T84 cells in culture as a model for enteroaggregative Escherichia coli pathogenesis. Infect Immun. 1996;64:4761-8.

63. Fujiyama R, Nishi J, Imuta N, et al. The shf gene of a Shigella flexneri homologue on the virulent plasmid pAA2 of enteroaggregative Escherichia coli 042 is required for firm biofilm formation. Curr Microbiol. 2008;56:474-80.

64. Czeczulin JR, Whittam TS, Henderson IR, et al. Phylogenetic analysis of enteroaggregative and diffusely adherent Escherichia coli. Infect Immun. 1999;67:2692-9.

65. Mohamed JA, Huang DB, Jiang ZD, et al. Association of putative enteroaggregative Escherichia coli virulence genes and biofilm production in isolates from travelers to developing countries. J Clin Microbiol. 2007;45:121-6.

66. Sheikh J, Czeczulin JR, Harrington S, et al. A novel dispersin protein in enteroaggregative Escherichia coli. J Clin Invest. 2002;110:1329-37.

67. Navarro-Garcia F, Elias WP. Autotransporters and virulence of enteroaggregative E. coli. Gut Microbes. 2011;2:13-24.

68. Henderson IR, Navarro-Garcia F, Desvaux M, et al. Type V protein secretion pathway: the autotransporter story. Microbiol Mol Biol Rev. 2004;68:692-744

69. Greenberg DE, Jiang ZD, Steffen R, et al. Markers of inflammation in bacterial diarrhea among travelers, with a focus on enteroaggregative Escherichia coli pathogenicity. J Infect Dis. 2002;185:944-9. 
70. Jiang ZD, Okhuysen PC, Guo DC, et al. Genetic susceptibility to enteroaggregative Escherichia coli diarrhea: polymorphism in the interleukin-8 promoter region. J Infect Dis. 2003;188:506-11.

71. Mercado EH, Ochoa TJ, Ecker L, et al. Fecal leukocytes in children infected with diarrheagenic Escherichia coli. J Clin Microbiol. 2011;49:1376-81.

72. Khan K, Konar M, Goyal A, Ghosh S. Enteroaggregative Escherichia coli infection induces IL-8 production via activation of mitogenactivated protein kinases and the transcription factors NF-kappaB and AP-1 in INT-407 cells. Mol Cell Biochem. 2010;337:17-24.

73. Goyal A, Konar M, Setia A, et al. Galactose specific adhesin of enteroaggregative $E$. coli induces IL-8 secretion via activation of MAPK and STAT-3 in INT-407 cells. Biochim Biophys Acta. 2010;1800:574-9.

74. Boll EJ, Struve C, Sander A, et al. Enteroaggregative Escherichia coli promotes transepithelial migration of neutrophils through a conserved 12-lipoxygenase pathway. Cell Microbiol. 2012;14: $120-32$.

75. Mohamed JA, DuPont HL, Flores J, et al. Single nucleotide polymorphisms in the promoter of the gene encoding the lipopolysaccharide receptor CD14 are associated with bacterial diarrhea in US and Canadian travelers to Mexico. Clin Infect Dis. 2011;52:1332-41.

76. Paul M, Tsukamoto T, Ghosh AR, et al. The significance of enteroaggregative Escherichia coli in the etiology of hospitalized diarrhoea in Calcutta, India and the demonstration of a new honeycombed pattern of aggregative adherence. FEMS Microbiol Lett. 1994;117:319-25.

77. Adachi JA, Ericsson CD, Jiang ZD, et al. Natural history of enteroaggregative and enterotoxigenic Escherichia coli infection among US travelers to Guadalajara, Mexico. J Infect Dis. 2002;185:1681-3.

78. Cravioto A, Tello A, Navarro A, et al. Association of Escherichia coli HEp-2 adherence patterns with type and duration of diarrhoea. Lancet. 1991;337:262-4.

79. Kliegman RM, Behrman RE, Jenson HB, et al. The pathophysiology of body fluids and fluid therapy. In: Nelson Textbook of Pediatrics, 18th ed. Elsevier Health Sciences 2007, Ch. 55.1.
80. Faure C. Role of anti diarrhoeal drugs as adjunctive therapies for acute diarrhoea in children. Int J Pediatr. 2013;2013:612403.

81. Sang WK, Oundo V, Schnabel D. Prevalence and antibiotic resistance of bacterial pathogens isolated from childhood diarrhoea in four provinces of Kenya. J Infect Dev Ctries. 2012;6:572-8.

82. Estrada-Garcia T, Cerna JF, Pacheco-Gil L, et al. Drug-resistant diarrheogenic Escherichia coli, Mexico. Emerg Infect Dis. 2005; $11: 1306-8$.

83. Ochoa TJ, Cleary TG. Effect of lactoferrin on enteric pathogens. Biochimie. 2009;91:30-4.

84. Cerna JF, Nataro JP, Estrada-Garcia T. Multiplex PCR for detection of three plasmid-borne genes of enteroaggregative Escherichia coli strains. J Clin Microbiol. 2003;4:2138-40.

85. Jenkins $\mathrm{C}, \mathrm{Tembo} \mathrm{M}, \mathrm{Chart} \mathrm{H}$, et al. Detection of enteroaggregative Escherichia coli in faecal samples from patients in the community with diarrhoea. J Med Microbiol. 2006;55:1493-7.

86. Jenkins C, van Ijperen C, Dudley EG, et al. Use of a microarray to assess the distribution of plasmid and chromosomal virulence genes in strains of enteroaggregative Escherichia coli. FEMS Microbiol Lett. 2005;253:119-24.

87. Huang DB, Mohamed JA, Nataro JP, et al. Virulence characteristics and the molecular epidemiology of enteroaggregative Escherichia coli isolates from travellers to developing countries. J Med Microbiol. 2007;56:1386-92.

88. Jenkins $\mathrm{C}$, Chart H, Willshaw GA, et al. Genotyping of enteroaggregative Escherichia coli and identification of target genes for the detection of both typical and atypical strains. Diagn Microbiol Infect Dis. 2006;55:13-9.

89. Nüesch-Inderbinen MT, Hofer E, Hächler H, et al. Characteristics of enteroaggregative Escherichia coli isolated from healthy carriers and from patients with diarrhoea. Med Microbiol. 2013;62:1828-34.

90. Huang DB, Mohanty A, DuPont HL, et al. A review of an emerging enteric pathogen: enteroaggregative Escherichia coli. J Med Microbiol. 2006;55:1303-11.

91. Zaidi MB, Estrada-Garcia T, Campos FD, et al. Incidence, clinical presentation, and antimicrobial resistance trends in Salmonella and Shigella infections from children in Yucatan, Mexico. Front Microbiol. 2013;4:288. 